\title{
Documenting the development of social capital in a community Safety Promotion Network: It's not what you know but who you know
}

\author{
Dale Hanson, Jan Hanson, Paul Vardon, Kathryn McFarlane, Rick Speare and David Dürrheim
}

\section{Introduction}

Injury is the fourth leading cause of death in Australia, and the leading cause of death in those under 45 years of age. ${ }^{1}$ Every year approximately 7,800 Australians die $^{1}$ and 330,000 are hospitalised $^{2}$ due to injury. Regional and rural communities experience greater morbidity and mortality due to injury. ${ }^{1,2}$ Injury has a complex aetiology caused by an intricate tapestry of behavioural, physical, environmental and social determinants. ${ }^{3,4}$ No single profession, organisation, community group or government sector possesses the expertise or resources necessary to design or implement a comprehensive multi-level and multi-sector solution. ${ }^{5}$ Stone et al. observe, "The main concern is how to bring about enough co-operation among disparate community elements to get things done. This is a 'power to' that, under many conditions of ultracomplexity, characterises the situation better than 'power over' (p354)". ${ }^{6}$

\begin{abstract}
Mackay Whitsunday Safe Communities
Mackay is a major regional centre in north Queensland, $1,200 \mathrm{~km}$ north of Brisbane and $300 \mathrm{~km}$ north of the Tropic of Capricorn. In 2001 it had a population of 128,000 .

In 1999, Mackay Base Hospital $(\mathrm{MBH})$ reported age standardised Emergency Department (ED) injury presentation rates were double those observed in South Brisbane, the major urban centre in the same State. ${ }^{7}$

The Mackay community had attempted to respond, but a needs analysis concluded, "Injury control activities in Mackay have been extensive but largely unco-ordinated. ... With many of the programs based on similar principles and strategies, a co-operative, systematic and inter-sectorial approach would be more productive." ${ }^{8}$
\end{abstract} Abstract

Issue addressed: The Mackay Whitsunday Safe Communities (MWSC) was established in February 2000 in response to high rates of injury observed in the region. A key objective was to consolidate and better coordinate a network of community groups already working in community safety promotion.

Methods: This study used Social Network Analysis (SNA) to document and analyse the social resources, or social capital, mobilised by the network. Using a snowballing methodology, the chain of relationships that constitute MWSC and its Support Network (SN) was elucidated and quantified.

Results: Since it was launched in February 2000, MWSC and its SN almost doubled its bonding social capital, while bridging social capital increased $160 \%$ and linking social capital increased $280 \%$. Relationships were not evenly distributed. Forty-four per cent of relationships were maintained by six actors who also maintained $60 \%$ of the network's brokerage potential.

Conclusion: SNA proved a powerful tool for describing and analysing relationships within the MWSC and its $\mathrm{SN}$. It provided diagrammatic representation of the social structure and quantified important aspects of its structure and function. It highlighted the asymmetric distribution of relationships, resources and power that had a profound impact on how the network functioned.

Keywords: social capital, social network analysis, safe communities, safety promotion, injury prevention

Health Promotion Journal of Australia 2008; 19:144-51

\section{So what?}

There is more than one type of social capital. Bonding social capital (an attribute of cohesive groups) enhanced cooperation, while bridging and linking social capital (an attribute of strategically connected individuals) accessed the resources necessary to maintain MWSC activities. 
Inspired by the Ottawa Charter for Health Promotion ${ }^{9}$ there is a rich tradition of community-based intervention for injury prevention and health promotion. ${ }^{10,11}$ Mackay Whitsunday Safe Communities (MWSC) was established using this community development model. By involving the community in finding and implementing its own solutions, it hoped to catalyse structural, social and political change that empowered the community and ultimately, individuals within the community, to change their environment and their behaviour to reduce the risk of injury. ${ }^{7}$

The World Health Organization (WHO) provided a comprehensive framework for promoting safety in communities. ${ }^{12}$ It aimed to designate Safe Communities as demonstration sites using six indicators of best practice in community safety promotion: ${ }^{10,12}$

1) An infrastructure based on partnerships and collaborations, governed by a cross-sectional group that is responsible for safety promotion in their community.

2) Long-term, sustainable programs covering both genders and all ages, environments and situations.

3) Programs that target high-risk groups and environments and programs that promote safety for vulnerable groups.

4) Programs that document the frequency and causes of injury.

5) Evaluation measures to assess their programs, processes, and the effects of change.

6) Ongoing participation in national and international Safe Communities Networks.

Submitting to this process of external review would provide a meaningful interim goal that would help engage local partners, facilitate best practice and enhance the credibility of the network, creating further opportunities to involve government, local organisations and business.

MWSC was endorsed by Mackay City Council (MCC) and Whitsunday Shire Council (WSC) and launched in February 2000. A cross-sectoral co-ordination group, the Network Support Group (NSG) was formed to facilitate development of the network. Existing domains of injury prevention and safety promotion were consolidated to form four initial action groups:

- Road Safety;

- Seniors Safety;

- Child Safety (Whitsunday);

- Injury Research.

Subsequently, action groups were formed on the basis of perceived need, results of local epidemiological studies and the availability of a sponsoring organisation to facilitate the group:

- The Alcohol and Injury Group (2001);
- ChIPP: The Mackay Child Injury Prevention Project (2003); and

- The Occupational Health and Safety (2003).

Team leaders of the action groups, provided the core membership of the Network Support Group supported by representatives from key stakeholders.

The coalition developed strategic links with other local groups working in Community Safety:

- Building Safe Communities Action Team working in crime prevention; and

- Whitsunday Schoolies Week Committee which aimed to provide a safe environment for senior students celebrating the end of school.

While these groups remained autonomous, MWSC worked collaboratively with these linked projects to develop and maintain joint initiatives.

By pooling expertise and resources from members of MWSC action groups, linked projects, local organisations, stakeholder organisations and state, national and international partners, MWSC sought to enhance its capacity to develop, implement and sustain interventions capable of reducing injury and promoting safety within the Mackay Whitsunday community.

In September 2004, MWSC staged the 2nd Pacific Rim WHO Safe Communities Conference and the 6th Australian Injury Prevention Conference in collaboration with the Australian Injury Prevention Network and was officially designated an 'International Safe Community' by the WHO Collaborating Centre on Community Safety Promotion. Age standardised ED injury presentations to Mackay Base Hospital had reduced from 76.4 per 1,000 in 2000 to 67.5 per 1,000 in $2004 .^{13}$

\section{Social capital}

Robert Putnam defined social capital as the "features of social organisation such as networks, norms, and trust that facilitate co-ordination and co-operation for mutual benefit" (p 169). ${ }^{14}$ A number of social researchers (particularly Bourdieu, ${ }^{15}$ Coleman $^{16}$ and Putnam ${ }^{17}$ ) have attempted to operationalise the concept.

Health research has been dominated by the 'social cohesion school' of social capital, ${ }^{18,19}$ championed by Putnam. ${ }^{17} \mathrm{~A}$ cohesive social network creates an environment in which social norms facilitate a reliable pattern of social interchange by restraining the fragmenting forces of social difference (different values, different ideas, and differential distribution of resources). Network members are constrained to behave in a predictable and socially acceptable way, enhancing trust and reducing the emotional, social and monetary cost of 
co-operating with others. In this paradigm social capital is a stabilising force that counters the excesses of the capitalist market which can produce environmental, structural and social inequalities associated with poor health. ${ }^{20,21}$ Cohesive social capital is an attribute of groups that have a network of strong, dense relationships which link members of similar social standing. ${ }^{22,23}$

Health researchers and practitioners are less familiar with the 'network school' of social capital. ${ }^{22-26}$ This paradigm conceives social capital as a set of resources, such as social support, information channels and social credentials, embedded in an individual's social network. ${ }^{18}$ Networks provide unequal opportunity and impose differing constraints on their members. In keeping with the early insights of Bourdieu ${ }^{15}$ and Coleman, ${ }^{16}$ asymmetric access to information, resources, opportunity and power may have profound impacts on the health and livelihood of individuals living within a social system. ${ }^{27-30}$

Mark Grannovetter in his paper The Strength of Weak Ties argued that some relationships are more strategic than others. ${ }^{31}$ Relationships that span the boundaries between groups offer unique information. These bridging relationships are typically 'weak ties'. Individuals who reside on the relational bridges connecting groups play a key role in any social interaction that depends on the productive exchange of resources, information or expertise between groups. ${ }^{22}$

Drawing on insights gained from both the social cohesion and the network schools of social capital, Szreter and Woolcock ${ }^{30}$ suggest a useful distinction can be drawn between 'bonding', 'bridging' and 'linking' social capital: 32,33

- Bonding social capital refers to the cohesive bonds (strong ties) that facilitate social relations within homogenous social groups.

- Bridging social capital refers to the weaker horizontal bridging relationships that connect dissimilar groups of equal social standing.

- Linking social capital refers to vertical relationships that connect actors (network members) across a hierarchy where power, status and wealth are unequally distributed.

This study sought to document and analyse the social process MWSC used to promote safety in the Mackay community. The process of working with the community to empower it to solve its own problems is a necessary, but not sufficient, part of community safety promotion. Clearly, the interventions implemented by MWSC action groups to address specific injury issues were important. ${ }^{34}$ However, they are beyond the purpose and scope of this paper.

\section{Method}

The MWSC used Social Network Analysis (SNA) ${ }^{24-26}$ to describe and analyse this community safety promotion network which included MWSC and its external support network (SN) consisting of local, (linked projects and local government) state, national and international organisations (politicians, government departments and non-government organisations).

A snowballing method was used to identify the network. ${ }^{26,34}$ Members of the NSG were initially sampled. They were asked to recall individuals with whom they interacted in their work of promoting safety in the community. They were also asked to retrospectively identify if they had a relationship with this person prior to their involvement in MWSC. These people did not necessarily need to be members of the MWSC. Network members identified by the NSG were followed up in wave one of the study. The chain of contacts was followed through two further survey waves, after which recruitment was terminated. During wave two, members of the MWSC not already identified were included in the survey. A MWSC member was defined as anyone minuted as having attended one or more meetings of one of MWSC's action groups.

Respondents were asked to identify the resources they shared via their relationships.

1. In-kind resources (including printed material, library access, desk space, office space, computer hardware or software).

2. Human resources (defined as sharing personal time outside formal meetings).

3. Financial resources (defined as sums greater than $\$ 100$ that once given were no longer under the direct control of the respondent or their organisation).

The study was approved by the Human Research Ethics Committee of James Cook University. Participation was voluntary and personal identifying information was confidential. Participants who had not returned their survey forms were followed up in writing and subsequently by telephone to ensure an optimum response rate. Three authors of this paper (D.H., P.V., K.M.) were members of MWSC and its SN. The study was commenced in December 2003 (initial sample) and completed in December 2004.

Network and actor attributes were calculated using UCINET 6.74 and NetDraw 1.45 software. $^{35}$

\section{Results}

At the launch in February 2000, the seven founding members of the NSG had a direct influence of 78 actors. 
These actors identified relationships with a further 67 actors, creating a network of 152 members (MWSC and its SN). Therefore, the NSG had a direct relationship with 56\% of the network.

By 2004, the direct sphere of influence of the NSG had nearly doubled to include 152 network members who in turn had access to 16 actors, creating a total network of 168, $90 \%$ of whom maintained a relationship with a member of the NSG.
One hundred and fourteen (67\%) were members of the MWSC, while 56 (33\%) were members of the SN. One hundred and forty-eight individuals agreed to participate, giving an overall response rate of $87 \%$. The observed structure of MWSC and its $\mathrm{SN}$ is shown in Figure 1.

Figure 2 compares the sociograms of MWSC and its SN at the time of project launch and the time of the study in 2004. The network had grown, but largely by increasing the number of relationships maintained by pre-existing members of the

Figure 1: Observed structure of Mackay Whitsunday Safe Communities and its Support Network.

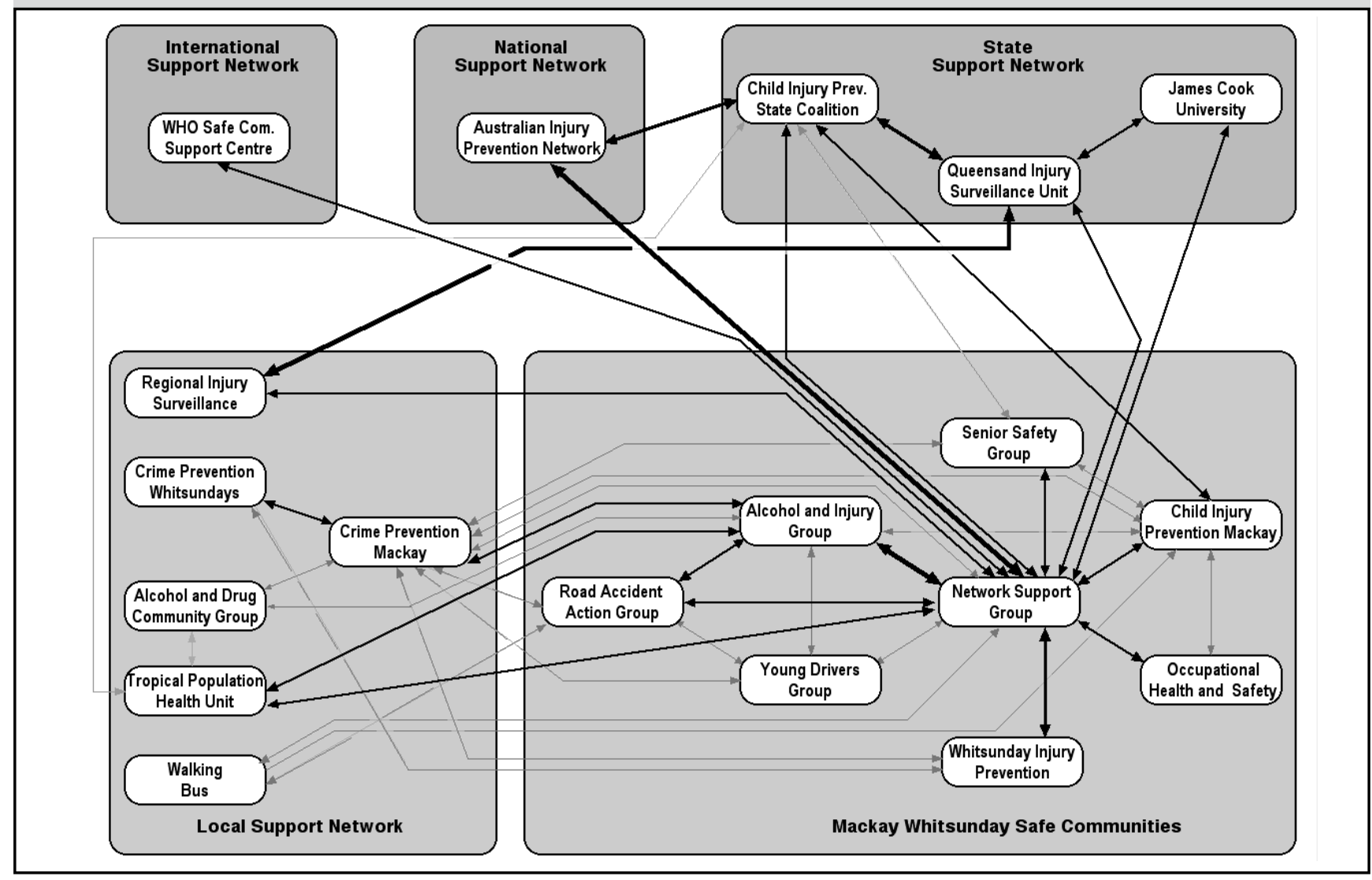

Figure 2: Sociogram of the MWSC and its SN, 2000 compared with 2004.
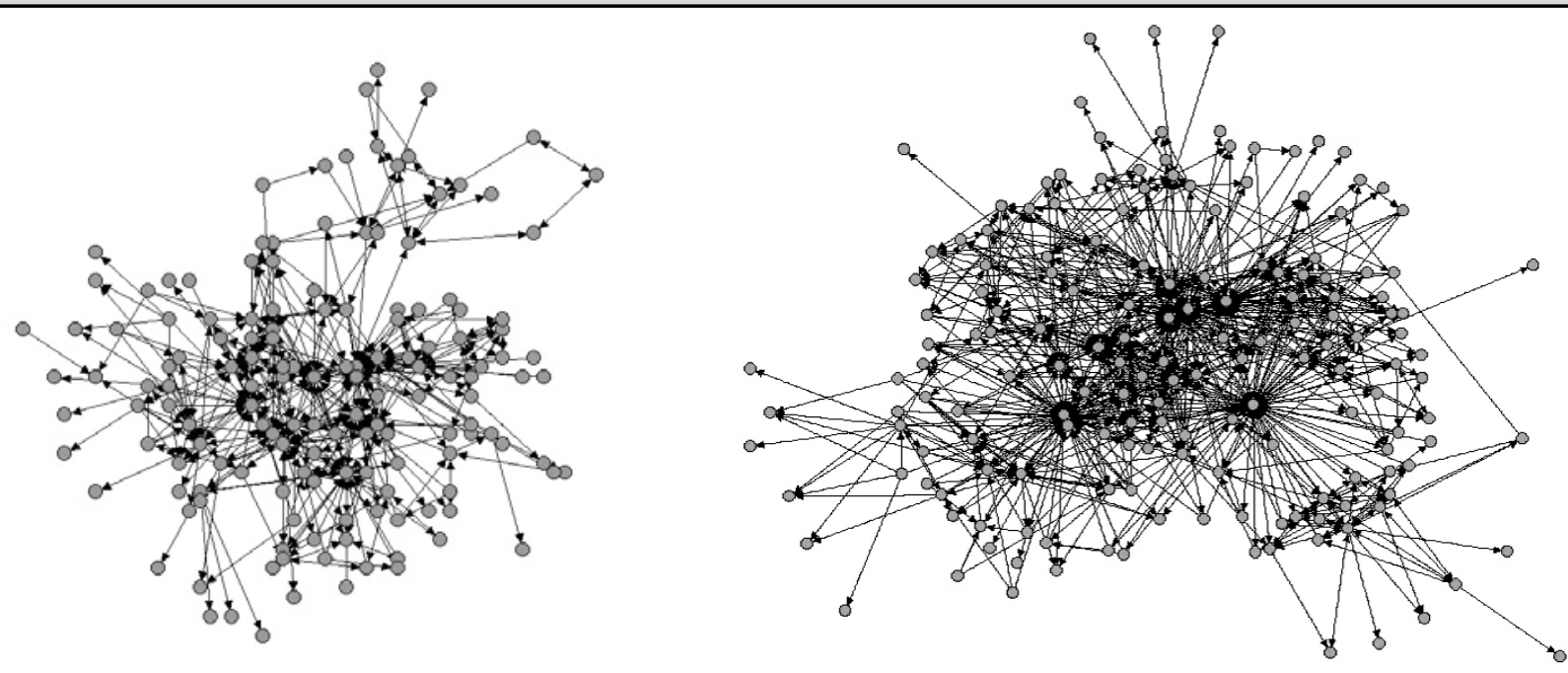
network. While the size of the network had increased from 152 in February 2000 to 168 by December 2004, relationships had doubled (500 to 1,002).

As a result, the cohesion of the network increased substantially (Table 1). The density of interpersonal relationships increased from 0.022 to $0.036(p=0.0002)$. The average number of relationships maintained by each actor (average degree) increased from 3.3 to 5.9 ( $p<0.000$, Wilcoxon 2 tailed). The average distance (the number of intermediaries) separating actors reduced from 3.9 to 2.8. The centralisation index increased from $18 \%$ to $43 \%$. Members of the network were more likely to be clustered in groups (clustering coefficient 0.30 in 2000 compared with 0.50 in December 2004).

Table 2 categorises network relationships in terms of internal bonding relationships, bridging relationships between MWSC and its local SN and linking relationships connecting MWSC to its state/national/international SN. In 2004 there were 615 bonding relationships (a 200\% increase), 117 bridging relationships (a 160\% increase) and 156 linking relationships (a $280 \%$ increase).

Degree centrality is a count of the number of relationships maintained by individual actors. Figure 3 indicates that degree centrality is a skewed distribution biased towards a small number of actors with very high degree centrality. Six highly connected actors had a degree centrality of $20 \%$ or above, together accounting for $44 \%$ of relationships observed in the network in 2004. They had tripled their bonding social capital, reporting 93 internal bonding relationships in 2000 which increased to 288 in 2004.

'Betweeness centrality' counts the number of occasions an actor is situated on the shortest pathway connecting two other actors. It is a measure of brokering potential. Figure 4 indicates

Table 1: Network cohesion, 2000 compared with 2004.

\begin{tabular}{lcc}
\hline & $\mathbf{2 0 0 0}$ & $\mathbf{2 0 0 4}$ \\
\hline Active members & 152 & 168 \\
Relationships & 500 & 1002 \\
Cohesion & & \\
- Density & 0.022 & $0.036(\mathrm{p}<0.0002)$ \\
- Average degree & 3.3 & $5.9(\mathrm{p}<0.000)$ \\
- Distance based cohesion & 0.18 & 0.34 \\
Average distance & 3.9 & 2.8 \\
Centralisation & $18 \%$ & $43 \%$ \\
Clustering co-efficient & 0.30 & 0.50 \\
\hline
\end{tabular}

Table 2: Bonding, bridging and linking relationships, 2000 compared with 2004.

\begin{tabular}{lccc}
\hline & $\mathbf{2 0 0 0}$ & $\mathbf{2 0 0 4}$ & Increase \\
\hline Bonding Relationships & 307 & 615 & $200 \%$ \\
Bridging Relationships & 72 & 117 & $160 \%$ \\
Linking Relationship & 56 & 156 & $280 \%$ \\
External Relationships & 65 & 114 & $175 \%$ \\
\hline
\end{tabular}

that 'betweeness centrality' was even more skewed. The six most connected actors accounted for $60 \%$ of the brokerage potential observed in the network. They were a rich source of bridging and linking social capital, maintaining $42 \%$ of the bridging relationships and $69 \%$ of the linking relationships.

The sharing of in-kind, human and financial resources was documented in 2004.

Sixty-three per cent of respondents shared in-kind resources. Half indicated that they shared printed materials, while $21 \%$ said they shared computer resources, $19 \%$ office space and $14 \%$ desk space.

Fifty-four per cent of relationships shared human resources mobilising 6.5 full time equivalents (FTE) within MWSC, more than half of which (3.6 FTE) was provided by the six most connected actors. The salaries of all MWSC members were externally funded.

Twenty-eight per cent of respondents shared financial resources mobilising approximately $\$ 910,000$. Funded activities of $\$ 660,000$ were directly related to MWSC, of which approximately $\$ 400,000(60 \%)$ funded the salaries of MWSC members. An amount of $\$ 250,000$ was invested in local infrastructure advocated by the MWSC to enhance community safety. Ninety-nine per cent of financial resources were accessed from the external SN. Forty-six per cent of financial resources were mobilised using bridging relationships while $53 \%$ of financial resources were mobilised using linking relationships.

The six most connected actors played an important role as facilitators of resource exchange, accessing $52 \%$ of the inkind resources, $54 \%$ of the human resources and $71 \%$ of the financial resources on behalf of MWSC.

Figure 3: Degree centrality, 2004.

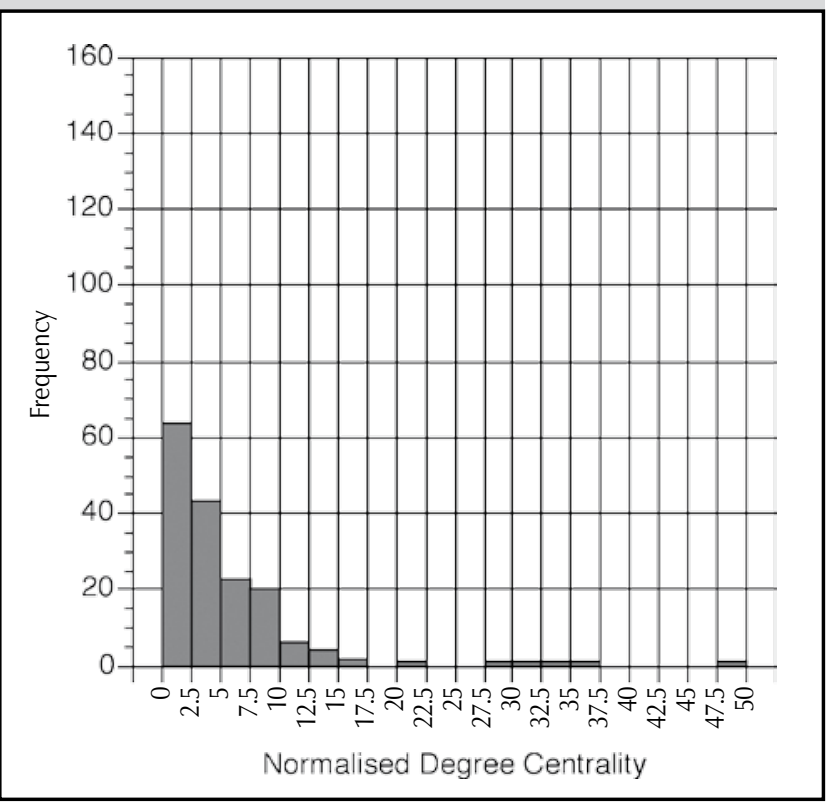




\section{Discussion}

A key objective of MWSC was to consolidate and better coordinate a network of community groups already working in the domain of community safety promotion..$^{4,7,8}$ SNA provided quantitative evidence that the network had engaged members and built social cohesion. By 2004, MWSC had created a network of 168 members, sharing 1,002 relationships. The average number of relationships maintained by network members (average degree) increased from 3.3 to 5.9. Network members demonstrated a stronger tendency to group formation (clustering coefficient increasing from 30\% to 50\%) and increased potential for co-ordination by a central group of actors (centralisation index increased from $20 \%$ to $43 \%$ ). Density increased from 0.022 to 0.036 ( $p<0.0002)$. MWSC had succeeded in building bonding social capital.

MWSC also enhanced its capacity to connect with external organisations, increasing bridging social capital by $160 \%$ and linking social capital by $280 \%$.

SNA provided compelling evidence that a small number of well-connected actors had disproportionate influence.

\section{Figure 4: Betweeness centrality, 2004.}

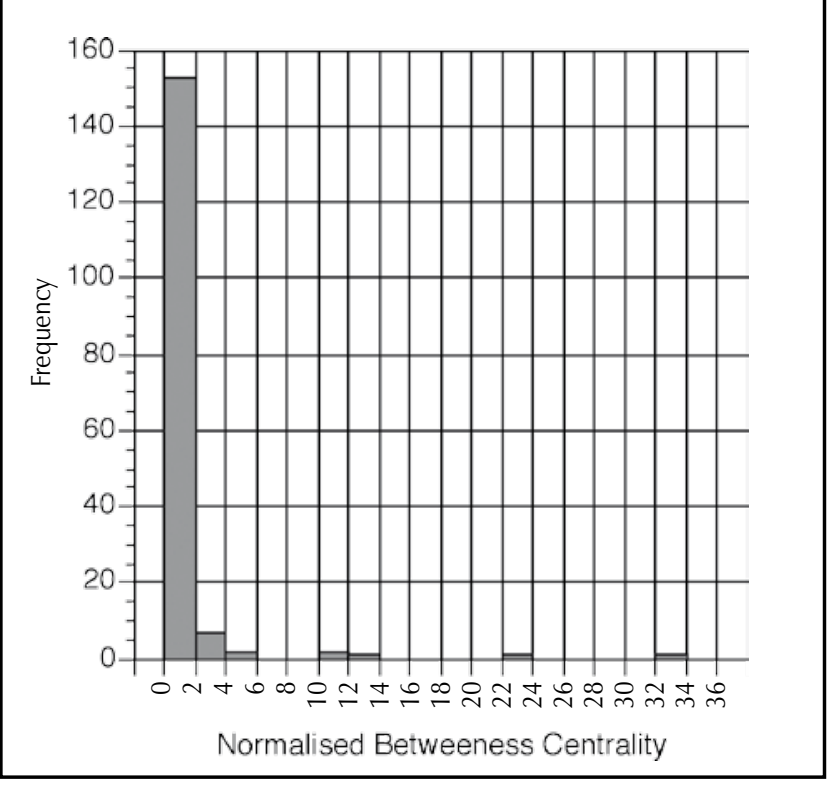

Whether measured in terms of direct social influence (degree centrality, Figure 3), brokerage (betweeness centrality, Figure 4) or exchange of resources, six network members wielded disproportionate influence. By 2004, they maintained 44\% of the relationships and $60 \%$ of the brokerage potential of the network which they used to access $52 \%$ of the inkind resources, $54 \%$ of the human resources and $71 \%$ of the financial resources mobilised by the network. These 'network facilitators' were members of the NSG and team leaders of MWSC action groups. They provided network bridges connecting the NSG to action groups, the action groups to each other, MWSC to its local support network and hierarchical links that connected MWSC to state, national and international organisations. By facilitating the exchange of information and resources, they empowered the network to negotiate, think and act.

Bourdieu observed that the brokering role of group advocates may not be solely a function of their personal social capital. ${ }^{15}$ He argued that groups often endorse public advocates that represent the values and credibility of the group. They wield the concentrated social capital of the group when they act on its behalf. Their success or failure, and in turn that of the group, is a function of the combined power of their personal bridging and linking social capital and the bonding social capital of the group. Burt provides empirical evidence to support this insight. ${ }^{22}$ He developed three-dimensional models mapping the impact of bonding, bridging and linking social capital on group effectiveness. Effective groups have a synergistic mix of all forms of social capital (Table 3).

MWSC was rich in social resources but poor in financial resources. It used its social capital to good effect, mobilising 6.5 FTE and \$900,000 to run programs and fund local safety infrastructure. Thus, in keeping with the economic metaphor,

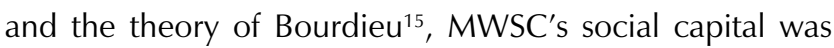
'fungible' - it was used to access other forms of capital.

Social capital is a valuable resource. However, it is not a free resource. It takes time to develop and maintain relationships. MWSC facilitators worked hard, together contributing 3.6 FTE and maintaining an average of 43 relationships per facilitator.

Table 3: Synthesis of the inter-relationship between bonding, bridging and linking social capital. ${ }^{22}$

\begin{tabular}{|c|l|l|}
\hline $\begin{array}{c}\text { High Bridging \& Linking } \\
\text { Social Capital }\end{array}$ & $\begin{array}{c}\text { Disintegrated group } \\
\text { A divisive group that is unable to integrate } \\
\text { the diverse perspectives, skills and resources } \\
\text { available to its members }\end{array}$ & $\begin{array}{l}\text { Maximum performance } \\
\text { A cohesive group that is able to integrate the } \\
\text { diverse perspectives, skills and resources } \\
\text { available to its members }\end{array}$ \\
\hline $\begin{array}{c}\text { Low Bridging \& Linking } \\
\text { Social Capital }\end{array}$ & $\begin{array}{l}\text { Minimum performance } \\
\text { A divisive group that is unable to integrate } \\
\text { alternate perspectives, skills or resources }\end{array}$ & $\begin{array}{l}\text { Group think } \\
\text { A cohesive group that only contains one perspective, } \\
\text { skill or resource }\end{array}$ \\
\hline & Low Bonding Social Capital & High Bonding Social Capital \\
\hline
\end{tabular}


Only a decade ago, social and health theorists were expressing concern about a conceptual slip that simultaneously conceived social capital as a macro attribute of the group and a micro attribute of an individual's interpersonal relationships. ${ }^{27,36-38}$ There is now a growing appreciation that there is more than one type of social capital acting at different levels of analysis. ${ }^{18,19,30,39}$ This study demonstrates all three forms of social capital. At the macro level - bonding social capital (an attribute of cohesive groups) and at the micro level - bridging and linking social capital (attributes of strategically connected individuals).

The network paradigm has much to offer health researchers and practitioners as a methodology, a theoretical system, and as a domain of research that has generated a substantial body of empirical evidence to explain how social phenomenon, such as social capital, work. ${ }^{18,19}$

In this study, the analytic tools of SNA unmasked the important impact of interpersonal relationships on the structure and function of MWSC. The asymmetric distribution of relationships, resources and, as a result, social power or social capital had a major impact on how MWSC and its SN worked. As much of the resource base necessary to run programs, especially financial resources, were accessed externally, the brokering role played by the network facilitators was critical to maintain the resource base of MWSC.

Inspired by insights gleaned from the network paradigm of social capital research, ${ }^{18,19-22}$ recent studies have highlighted the health promoting power of bridging and linking social capital while expressing concern that bonding social capital may be a health liability. ${ }^{40}$ Existing theoretical and empirical evidence from the network paradigm helps interpret these observations. Network analysts argue bonding social capital maintains group standards by enforcing social norms. It maintains the status quo. ${ }^{17,22,23}$ Bridging and linking social capital provide access to ideas and resources embedded in a network. They are important sources of innovation and creativity. Bridging and linking social capital promote change. ${ }^{22,23}$ Whether bonding, bridging or linking social capital are 'good' or 'bad' is not a function of the type of social capital, but whether the prevailing social norm in the target group is health promoting or a health impediment. If the objective is to reinforce a prevailing social norm, bonding social capital is necessary. If the objective is to change the prevailing social norm, bridging and linking social capital are needed.

\section{Conclusion}

SNA proved a powerful tool for describing and analysing relationships within the MWSC and its SN. It provided diagrammatic representation of the social structure and quantified important aspects of the structure and function of MWSC and its SN. It highlighted the asymmetric distribution of relationships, information, resources and power that had a profound impact on how the network functioned.

This study identified more than one type of social capital acting at different levels of analysis. Bonding social capital (a quality of cohesive groups) enabled MWSC to co-operate, while bridging and linking social capital (a quality of strategically connected individuals) were required to engage the external organisations that provided the resource base for MWSC activities.

\section{References}

1. Kreisfeld R, Newson R, Harrison JE. Injury Deaths, Australia 2002. Adelaide (AUST): Australian Institute of Health and Welfare; 2004. Injury Research and Statistics Series No.: 23.

2. Berry JG, Harrison JE. Hospital Separations Due to Injury and Poisoning Australia 2001-02. Adelaide (AUST): Australian Institute for Health and Welfare; 2006. Injury Research and Statistics Series.

3. Bonnie RJ, Fulco CE, Liverman CT, editors. Reducing the Burden of Injury, Advancing Prevention and Treatment. Washington (DC): Committee on Injury Prevention and Control, Institute of Medicine, National Academy Press; 1999.

4. Hanson DW, Hanson JL, Vardon P, McFarlane K, Lloyd J, Muller R, et al. The injury iceberg: an ecological approach to planning sustainable community safety interventions. Health Promot J Austr. 2005;16(1):5-10.

5. Cohen L, Aboelata M, Gantz T, Van Wert J. Collaboration Math: Enhancing the Effectiveness of Multidisciplinary Collaboration. Berkley (CA): Institute of Transportation Studies, Berkley Traffic Safety Center, University of California; 2003.

6. Stone C, Doherty K, Jones C, Ross T. School and disadvantaged neighbourhoods: the community development challenge. In: Ferguson RF, Dickens WT, editors. Urban Problems and Community Development. Washington (DC): Brookings Institution; 1999.

7. Vardon P, Hanson DW, Muller R, Miles E. Safe communities - an approach to injury prevention. Injury Bulletin. 2000;63:1-4.

8. Repper J, Vardon P. Project Plan: Mackay Safe Commmunities Project. Mackay (AUST): Tropical Population Health Network, Queensland Health; 1999.

9. World Health Organization. Ottawa Charter for Health Promotion. Ottawa (CAN): WHO; 1986.

10. Coggan C, Bennett S. Community-based injury prevention programs. In: McClure R, Stevenson M, McEvoy S, editors. The Scientific Basis of Injury Prevention and Control. Melbourne (AUST): IP Publishing; 2004. p. 347-58.

11. Gielen AC, Sleet DA, Green LW. Community models and approaches for interventions. In: Gielen AC, Sleet DA, DiClemente RJ, editors. Injury and Violence Prevention: Behavioural Science Theories, Methods and Applications. San Francisco (CA): Jossey Bass; 2006.

12. World Health Organization Collaborating Centre on Community Safety Promotion. Safe Communities. Stockholm (SWE): Department of Public Health Sciences, Division of Social Medicine, Karolinska Institute; 2005.

13. Hanson DW, Hockey R, Miles E, Muller R, Pitt R. Collection of NDS-IS level 2 Injury Surveillance Data in Regional Queensland. In: Muller R, editor. Reducing Injuries in Mackay, North Queensland. Warwick: Warwick Educational Publishing; 2002: 1-16.

14. Putnam RD, Leonardi R, Nanetti RY. Making Democracy Work: Civic Traditions in Modern Italy. Princeton (NJ): Princeton University Press; 1993.

15. Bourdieu P. The Forms of Capital. In: Richardson JG, editor. The Handbook of the Theory and Research for the Sociology of Education. New York (NY): Greenwood Press; 1986. p. 241-58.

16. Coleman JS. Social capital in the creation of human capital. AJS. 1988;94: S95-S120.

17. Putnam RD. Bowling Alone: The Collapse and Revival of American Community. New York (NY): Simon and Schuster; 2000.

18. Kawachi I. Social capital and health - making the connections one step at a time. Int J Epidemiol. 2006;35(4):989-93.

19. Moore S, Shiell A, Hawe P, Haines VA. The priveleging of communitarian ideas: citation practices and the translation of social capital into public health research. Am J Public Health. 2005;95:1330-7.

20. Kawachi I, Kennedy BP, Lochner K, Prothrow-Smith D. Social Capital, income equality, and mortality. Am J Public Health. 1997;87(9):1491-8.

21. Wilkinson R. Unhealthy Societies: The Afflictions of Inequality. London (UK): Routlege; 1996. 
22. Burt RS. Brokerage and Closure. Oxford (UK): Oxford University Press; 2005.

23. Lin N. Social Capital: A Theory of Social Structure and Action. Cambridge (UK): Cambridge University Press; 2001.

24. Borgatti SP, Foster PF. The Network Paradigm in Organisational Research: A Review and a Typology. Journal of Management. 2003;29(6):991-1013.

25. Lakon CM, Godette DC, Hipp JR. Network-based approaches for measuring social capital. In: Kawachi I, Subramanian SV, Kim D, editors. Social Capital and Health. New York (NY): Springer; 2008.

26. Scott J. Social Network Analysis: A Handbook. 2nd ed. London (UK): SAGE Publications; 2000.

27. Hawe P, Shiell A. Social capital and health promotion. Soc Sci Med. 2000;51(6):871-85.

28. Lynch J, Due P, Muntaner C, Davey Smith G. Social capital - is it a good investment for public health? J Epidemiol Community Health. 2000;54(6):404-8.

29. Szreter S. The state of social capital: bringing back in power, politics and history. Theory and Society. 2002;31(5):573-621.

30. Szreter S, Woolcock W. Health by Association? social capital, social theory, and the political economy of public health. Int J Epidemiol. 2004;33(4):650-67.

31. Granovetter MS. The strength of weak ties. AJS. 1973;78(6):1360-80.

32. Gittell R, Vidal A. Community Organizing: Building Social Capital as a Development Strategy. Thousand Oaks (CA): Sage Publications; 1998.
33. Narayan D. Bonds and Bridges: Social Capital and Poverty. Washington (DC): World Bank; 1999. p. 1-60. Policy Research Working Paper No.: 2167.

34. Hanson DW. Community Safety Promotion Networks: From Metaphor to Methodology. Townsville (AUST): James Cook University; 2007. Available from: http://eprints.jcu.edu.au/1751/

35. Borgatti SP, Everett M, Freeman L. UCINET 6 for Windows. Harvard (MA): Analytic Technologies; 2002.

36. Macinko J, Starfield B. The Utility of Social Capital in Research on Health Determinants. Milbank Q. 2001;79(3):387-427.

37. Portes A. The two meanings of social capital. Sociological Forum. 2000;15(1):112.

38. Woolcock M. The place of social capital in understanding social and economic outcomes. Canadian Journal of Policy Research. 2001;2(1):11-17.

39. Kawachi I, Subramanian SV, Kim D. Social capital and health: a decade of progress and beyond. In: Kawachi I, Subramanian SV, Kim D, editors. Social Capital and Health. New York (NY): Springer; 2008.

40. Kim D, Subramanian SV, Kawachi I. Social capital and physical health: a systematic review of the literature. In: Kawachi I, Subramanian SV, Kim D, editors. Social Capital and Health. New York (NY): Springer, 2008.

\section{Authors}

Dale Hanson, School of Medicine and Dentistry, James Cook University, Mackay, Queensland

Jan Hanson, Tropical Medical Training, Mackay, Queensland

Paul Vardon, Health Promotion Unit, Queensland Health

Kathryn McFarlane, Tropical Population Health Network, Queensland Health

Rick Speare, School of Public Health, Tropical Medicine and Rehabilitation Science, James Cook University, Townsville, Queensland

David Dürrheim, Hunter New England Health, Newcastle, New South Wales

Correspondence

Dale Hanson, Mackay Base Hospital, PO Box 5580, Mackay Mail Centre, Qld 4741. Tel: (07) $49686638 ;$

e-mail: dwhanson@matilda.net.au 